\title{
Comparison of invertebrate diversity in lake waters and their resting eggs in sediments, as revealed by high-throughput sequencing (HTS)
}

\author{
Xiaoyan Wang ${ }^{1,2}$, Qing Wang ${ }^{1,2, *}$, Yufeng Yang ${ }^{1,2}$ and Wenbo $\mathrm{Yu}^{1,2}$ \\ ${ }^{1}$ Department of Ecology, Jinan University, Guangzhou 510632, PR China \\ 2 Southern Marine Science and Engineering Guangdong Laboratory (Zhuhai), Zhuhai 519000, PR China
}

Received: 2 December 2019 / Accepted: 19 March 2020

\begin{abstract}
Aquatic invertebrate diversity reflects water quality and the health of aquatic ecosystems and should be monitored as an essential feature of freshwater ecosystems. The resting eggs of aquatic invertebrates in sediments populate the overlying water. The diversity of invertebrates in waters and their resting eggs in sediments in Baiyangdian Lake, Xiongan, North China, were assessed using high-throughput sequencing (HTS) with a pair of $18 \mathrm{~S}$ rRNA gene adaptor-linked primers. The total of 99 operational taxonomic units (OTUs) derived from 353,755 invertebrate sequences (mostly zooplankton) were revealed by this study. A total of 50 species in the water samples including 20 rotifers, 11 copepods, 1 cladoceran and 18 other species were sorted out. In the sediment 37 species, including 21 rotifers, 3 copepods, 1 cladoceran and 12 other species, were identified. There were 24 species in common between water and corresponding sediments. Invertebrate OTU richness in water samples was higher than that in sediments $(p<0.01)$, while there was no significant difference in the Shannon-Wiener index. These results suggest that HTS is a promising alternative for efficient biodiversity assessment and monitoring.
\end{abstract}

Keywords: zooplankton / copepod / cladoceran / rotifer / species diversity

Résumé - Comparaison de la diversité des invertébrés dans les eaux lacustres et de leurs œufs au repos dans les sédiments, telle que révélée par le séquençage à haut débit (HTS). La diversité des invertébrés aquatiques reflète la qualité de l'eau et la santé des écosystèmes aquatiques et doit être surveillée en tant que caractéristique essentielle des écosystèmes d'eau douce. Les œufs d'invertébrés aquatiques au repos dans les sédiments peuplent les eaux sous-jacentes. La diversité des invertébrés dans les eaux et de leurs œufs au repos dans les sédiments du lac Baiyangdian, à Xiongan, dans le nord de la Chine, a été évaluée à l'aide d'un séquençage à haut débit (HTS) avec une paire d'amorces liées à un adaptateur de gène d'ARNr 18S. Cette étude a révélé un total de 99 unités taxonomiques opérationnelles (OTU) dérivées de 353755 séquences d'invertébrés (principalement du zooplancton). Un total de 50 espèces dans les échantillons d'eau, dont 20 rotifères, 11 copépodes, 1 cladocère et 18 autres espèces ont été identifiées. Dans les sédiments, 37 espèces, dont 21 rotifères, 3 copépodes, 1 cladocère et 12 autres espèces, ont été identifiées. Il y avait 24 espèces en commun entre l'eau et les sédiments correspondants. La richesse en OTU d'invertébrés des échantillons d'eau était supérieure à celle des sédiments $(p<0,01)$, tandis qu'il n'y avait pas de différence significative dans l'indice de Shannon-Wiener. Ces résultats suggèrent que l'HTS est une alternative prometteuse pour une évaluation et un suivi efficaces de la biodiversité.

Mots clés : zooplancton / copépode / cladocère / rotifère / diversité des espèces

\section{Introduction}

Zooplankton and other aquatic invertebrates play an essential role in the ecology of aquatic ecosystems (González

\footnotetext{
*Corresponding author: wq2010@jnu.edu.cn
}

et al., 2018). Some invertebrates are sensitive to changes in water quality and therefore are indicators of water quality (Berraho et al., 2019). In different aquatic invertebrates, dormancy, where present, is expressed at various ontogenetic stages, from eggs to adults, but in a given taxon, it commonly occurs at only one of these stages (Radzikowski, 2013). The production of dormant forms is a common feature in aquatic 
invertebrates including Nematoda, Ostracoda, Cladocera, Copepoda, Rotifera, ciliates, jellyfish (Radzikowski, 2013; Fontaneto, 2019). Most aquatic invertebrates have two life stages: active forms in water and dormant forms, such as resting eggs, in sediment. In fact, dormant forms are characteristically able to maintain viability despite being exposed to environmental extremes that would kill their active forms (Radzikowski, 2013). For example, eutrophic conditions could lead Daphnia to allocate more energy to reproduction, which is a reasonable strategy to ameliorate the risks from low quality food (Zhou et al., 2020). A resting egg is therefore an important survival strategy for planktonic invertebrates to resist periodic harsh conditions (Radzikowski, 2013). Resting eggs are also resistant to anthropogenic factors such as heavy metals, organic pollutants and ionizing radiation (Zadereev et al., 2019). Egg banks in the surface sediments of lakes are a source of resting eggs that insures maintaining their populations which represent the persistence of genetic diversity. They play an important role in the biogeochemical cycle. Sediments are, therefore, the main storage sites for the overwintering planktonic community (Holm et al., 2018).

Quantifying the biodiversity of temperate lakes is necessary to assess their ecosystem services for establishing water quality. For example, species diversity and richness of cladoceran resting eggs hatched from sediments was higher than that in the active water community (Vandekerkhove et al., 2005a). Furthermore, resting eggs in sediments supplemented by planktonic invertebrates (Santangelo et al., 2015) were similar to the plankton and resting egg community. Therefore, we compare the diversity of aquatic invertebrates in water and sediment using a novel genetic tool, with the traditional methods. We also wish to test the observation that the diversity of aquatic invertebrates in water is lower than that in sediment.

Biodiversity assessments are particularly difficult for short-lived communities, such as microzooplankton (Lindeque et al., 2013; Zhan et al., 2013; Hirai et al., 2015). Also, the traditional methods using microscopy to characterize the aquatic invertebrate community or sediment hatching are timeconsuming and limited (Savin et al., 2004; Lee et al., 2010; Egge et al., 2015). In recent years, DNA sequencing has become an alternative approach by pyrosequencing and molecular phylogenetics (Hajibabaei et al., 2011; Chai et al., 2018). The V4 region of $18 \mathrm{~S}$ rRNA gene, is variable, long and highly uniform. It is a reliable, quick and costeffective identification system suitable for high-throughput sequencing (HTS) (Cheung et al., 2010). HTS data is a powerful tool to describe the community structure of shortlived organisms (Chust et al., 2017). For example, Mohrbeck et al. (2015) reported the taxonomic diversity of marine protist communities in six separate European coastal waters and sediments sites by HTS, and more species were identified using the $18 \mathrm{~S}$ rDNA gene than by morphology. The detection of aquatic invertebrate species from resting eggs in the sediments of lakes is problematic, because few can be identified to species level by morphology (Vandekerkhove et al., 2005b). Therefore, we used the 18S rRNA gene of the V4 region to analyze both the water and sediment samples.

Baiyangdian Lake, the "Pearl of north China", in the Xiongan New Area, is the largest freshwater body and the largest inland shallow lake wetland in the North China. It
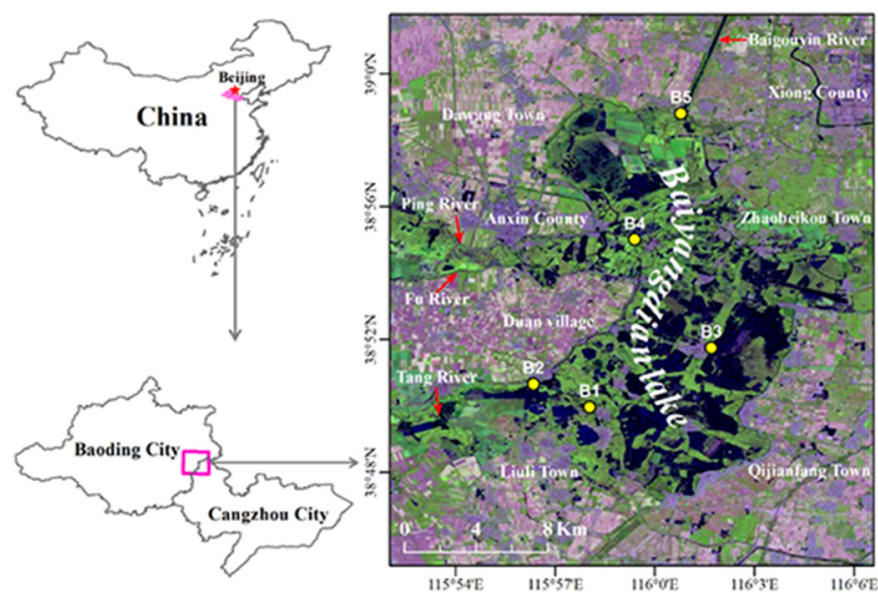

Fig. 1. Sampling sites in Baiyangdian Lake.

plays an important role in water purification and circulation of underground water (Wang et al., 2015). The objective of this study is to analyze the aquatic invertebrate diversity in Baiyangdian Lake using HTS technology. More specifically, our aims were to (1) determine if any new biodiversity was revealed compared to earlier methods and (2) to compare aquatic invertebrate diversity between waters and sediments.

\section{Materials and methods}

\subsection{Sample collection and DNA extraction}

Lake Baiyangdian $\left(38^{\circ} 49^{\prime}-38^{\circ} 59^{\prime} ; 115^{\circ} 56^{\prime}-116^{\circ} 5^{\prime}\right)$ is a typical shallow lake in Baoding City, North China, formed under a warm temperate continental monsoon climate. The lake actually consists of hundreds of interconnected small, shallow lakes. The total area of the lake is $366 \mathrm{~km}^{2}$, the maximum storage capacity is about $7 \times 10^{9} \mathrm{~m}^{3}$, and the average water depth is $3.6 \mathrm{~m}$. Five sampling sites (B1/B2/ B3/B4/B5) were selected according to lake shape, hydrodynamic characteristics and water quality. Five water samples (W1/W2/W3/W4/W5) and sediment samples (S1/S2/S3/S4/ S5) were collected at the five sites from the lake on September 25, 2018 (Fig. 1). This season was suitable for sampling resting eggs and some invertebrate species disappearing from the water in winter. Some basic information of environmental parameters at the five sampling sites is shown in Table 1.

Water samples were collected with a $20 \mu \mathrm{m}$ mesh plankton net, and plankton net was trawled vertically and horizontally to collect invertebrates from all depth. Samples were transferred into $50 \mathrm{~mL}$ polyethylene containers. Water samples were collected by filtering the water through polycarbonate membranes (PM, $47 \mathrm{~mm}, 5 \mu \mathrm{m}$; EMD Millipore GTPP04700, USA). Genomic DNA was extracted by ALFA - SEQ Advance Water DNA Kit (Guangzhou microchip biological technology co. LTD, Guangzhou) and then stored at $-80^{\circ} \mathrm{C}$.

Sediment samples were collected with a Petersen dredge from upper $0.5 \mathrm{~m}$ surface. Subsamples $(80 \mathrm{~g})$ were selected and resting eggs were extracted by the sugar flotation method 
X. Wang et al.: Knowl. Manag. Aquat. Ecosyst. 2020, 421, 19

Table 1. Detailed information at five sampling sites. DO: dissolved oxygen, Chl- $a$ : chlorophyll $a$, TP: total phosphorus, TN: total nitrogen.

\begin{tabular}{lllllll}
\hline & B1 & B2 & B3 & B4 & B5 & Measuring method \\
\hline Temperature $\left({ }^{\circ} \mathrm{C}\right)$ & 21 & 21.5 & 22.2 & 21 & 21.4 & \\
Salinity & 0.71 & 0.65 & 0.62 & 0.39 & 0.35 & Multiprobe (YSI-Plus, USA) \\
pH & 8.49 & 8.27 & 8.34 & 8.57 & 8.21 & \\
DO $(\mathrm{mg} / \mathrm{L})$ & 4.45 & 5.04 & 6.21 & 3.4 & 5.71 & \\
Chl $-a(\mu \mathrm{g} / \mathrm{L})$ & 15 & 45 & 37 & 20 & 12 & Standard analytical methods \\
TP $(\mu \mathrm{mol} / \mathrm{mL})$ & 0.079 & 0.08 & 0.028 & 0.03 & 0.105 & (GB3838-2002, MEE, China, 2002) \\
TN $(\mu \mathrm{mol} / \mathrm{mL})$ & 0.525 & 1.423 & 0.913 & 2.146 & 1.289 & \\
\hline
\end{tabular}

(Onbé, 1978). Genomic DNA of resting eggs was extracted with DNeasy Power Soil Kit (QIAGEN 12888, Germany) and stored at $-80^{\circ} \mathrm{C}$.

\subsection{PCR and Illumina Miseq sequencing}

A pair of adaptor-linked primers (forward 528F5'GCGGTAATTCCAGCTCCAA-3' and reverse 760R 5'-AATCCRAGAATTTCACCTCT-3') flanking the hypervariable V4 region of the $18 \mathrm{~S}$ rRNA gene was used for PCR amplification (Cheung et al., 2010). The PCR reaction used the following program: 3 min of denaturation at $94{ }^{\circ} \mathrm{C}$, followed by 30 cycles of $30 \mathrm{~s}$ at $94^{\circ} \mathrm{C}, 30 \mathrm{~s}$ at $60^{\circ} \mathrm{C}, 1 \mathrm{~min}$ at $72^{\circ} \mathrm{C}$ and a final extension at $72^{\circ} \mathrm{C}$ for $5 \mathrm{~min}$. PCR reactions were performed in triplicate $20 \mu \mathrm{L}$ mixture containing $4 \mu \mathrm{L}$ of $5 \times$ FastPfu Buffer, $2 \mu \mathrm{L}$ of $2.5 \mathrm{mM}$ dNTPs, $0.8 \mu \mathrm{L}$ of each primer $(5 \mu \mathrm{M}), 0.4 \mu \mathrm{L}$ of FastPfu Polymerase and $10 \mathrm{ng}$ of template DNA. The PCR products were extracted from a $2 \%$ agarose gel and further purified using the AxyPrep DNA Gel Extraction Kit (Axygen Biosciences, Union City, CA, USA) and quantified using QuantiFluor ${ }^{\mathrm{TM}}$-ST (Promega, USA) according to the manufacturer's protocol. Purified amplicons were pooled in equimolar and paired-end sequenced $(2 \times 300)$ on an Illumina Miseq platform (Illumina, San Diego, USA). Sequencing service was achieved in the Shanghai Meiji Sequencing Centre.

\subsection{Analysis of the Illumina Miseq data}

Raw FASTQ files were demultiplexed, quality-filtered by Trimmomatic and merged by FLASH. After sequence screening, operational taxonomic units (OTUs) were clustered with a $97 \%$ similarity cutoff using UPARSE (version $7.1 \mathrm{http}: / /$ drive 5.com/uparse/) and chimeric sequences were identified and removed using UCHIME. The taxonomy of each $18 \mathrm{~S}$ rRNA gene sequence was analyzed by RDP Classifier algorithm (http://rdp.cme.msu.edu/) against the NT 18S rRNA gene database using $70 \%$ confidence threshold. Finally, the corresponding species information of each OUT was obtained.

Rarefaction curves were plotted on OUT level by using mothur for each station. Heatmap figures were generated using the $R$ package vegan. Venn diagrams were generated with online tools to show the common and unique species in water and sediment samples (http://bioinformatics.psb.ugent.be/ webtools/Venn/). Alpha diversity parameters (including Ace, Shannoneven index, Shannon-Wiener index and Simpson

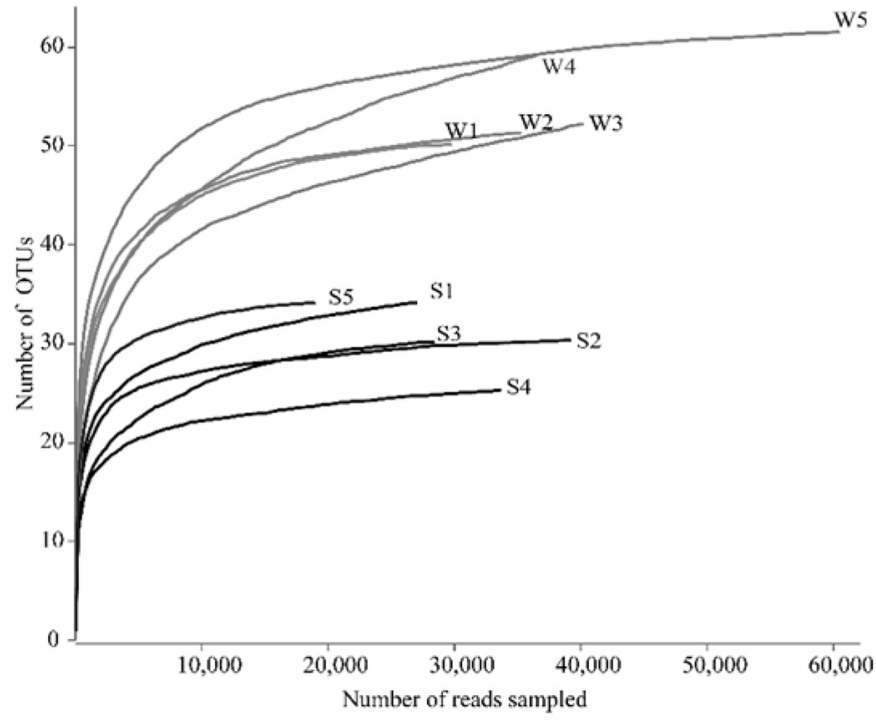

Fig. 2. Rarefaction curve of repeat samples.

index) on the OTU level were conducted by mothur software. Using the $R$-stats and the python-scipy though Wilcoxon ranksum test compared the relative abundance difference and significance level of species between water and sediment samples. All test significance levels were set at 0.05 .

\subsection{Sequence signatures}

Illumina Miseq sequencing runs provided a total of $1,069,096$ raw sequence reads. After splicing and removing low-quality sequences, 353,755 complete high-quality eukaryotic invertebrate V4 sequences with an average length of $330 \mathrm{bp}$ were obtained. High-quality sequences were classified and labeled. These sequences were clustered into a total of 99 OTUs of invertebrates using a 97\% similarity cutoff. Nontarget OTUs belonging to bacteria, fungi, or phytoplankton were removed from further analyses. All subsequent analyses were based on invertebrate metabarcoding data. All raw reads of this study were deposited in the NCBI database (Accession number: PRJNA558873).

Most of the rarefaction curves for the samples were saturated (Fig. 2), indicating sufficient sequencing depth for this study. The sequencing data volume was reasonable and 
Table 2. The diversity indices of invertebrates in Baiyangdian Lake; Sob: observed species richness, Shannon: Shannon diversity index, Simpson: Simpson diversity index, Ace: abundance-based coverage estimator, Shannoneven: a Shannon index-based measure of evenness, Simpson even: a Simpson index-based measure of evenness.

\begin{tabular}{lllllll}
\hline Sample & Sob & Shannon & Simpson & Ace & Shannoneven & Simpsoneven \\
\hline W1 & 50 & 2.296 & 0.152 & 50.438 & 0.587 & 0.132 \\
S1 & 34 & 1.804 & 0.273 & 37.974 & 0.512 & 0.108 \\
W2 & 51 & 2.395 & 0.133 & 52.304 & 0.609 & 0.147 \\
S2 & 30 & 1.760 & 0.259 & 30.675 & 0.517 & 0.129 \\
W3 & 52 & 0.987 & 0.655 & 61.895 & 0.250 & 0.029 \\
S3 & 30 & 1.639 & 0.257 & 31.007 & 0.482 & 0.130 \\
W4 & 59 & 2.301 & 0.144 & 71.015 & 0.564 & 0.117 \\
S4 & 25 & 1.787 & 0.236 & 27.839 & 0.555 & 0.170 \\
W5 & 61 & 2.209 & 0.191 & 62.661 & 0.537 & 0.227 \\
S5 & 34 & 2.278 & 0.129 & 34.690 & 0.646 & - \\
W-total & - & 3.811 & 0.119 & - & - & 0.1291 \\
S-total & - & 2.927 & 0.206 & - & - & 0.6588 \\
$P$ value & 0.000026 & 0.5388 & 0.8204 & 0.000176 & & \\
\hline$P$ valye & & & & & &
\end{tabular}

$P$ value: t-test between the water and sediment samples.

large enough to reflect the diversity information of most invertebrates in the samples.

\section{Results}

\subsection{Comparisons of invertebrate community between water bodies and sediments}

\subsubsection{Overall taxonomic richness}

Taxonomic annotation of OTUs was assigned according to the best BLASTN hit against the NCBI-NT reference database. All invertebrate OTUs were further classified to different taxonomical levels from species to kingdom (Fig. 3). All invertebrate sequences belong to 99 OTUs, 63 species, 55 genera, 41 families, and 9 phyla.

In the water samples, all sequences were classified into 9 phyla, 33 families, 45 genera, 50 species and 83 OTUs. The majority of invertebrate sequences from the water samples belonged to Arthropoda accounting for $60.88 \%$ of the total, and the second largest were Rotifera which accounted for $38.58 \%$, followed by Mollusca $(0.06 \%)$, Gastrotricha $(0.03 \%)$, Bryozoa (0.01\%), Nematoda (0.01\%), Entoprocta $(0.004 \%)$, Platyhelminthes $(0.001 \%)$, and unclassified $(0.44 \%)$. The 83 OTUs included 41 Arthropoda (49.40\%), 27 Rotifera (32.53\%), 4 Nematoda (4.82\%), 3 Gastrotricha (3.61\%), 2 Bryozoa (2.41\%), 1 Platyhelminthes (1.20\%), 1 Entoprocta $(1.20 \%), 1$ Mollusca (1.20\%), and 3 unclassified (3.61\%).

In the sediment samples, all sequences were classified into 5 phyla, 27 families, 33 genera, 37 species, 45 OTUs. The majority of invertebrate sequences from resting eggs in the sediments belonged to Rotifera $(78.44 \%)$, and the second largest was Arthropoda (19.16\%), followed by Bryozoa $(1.91 \%)$, Platyhelminthes $(0.48 \%)$ and Nematoda $(0.01 \%)$. The 45 OTUs included 27 Rotifera (60\%), 10 Arthropoda (22.22\%), 4 Platyhelminthes $(8.89 \%), 3$ Bryozoa (6.67\%), and 1 Nematoda $(2.22 \%)$.

The changes in invertebrate diversity in water and sediment showed opposite trends: rotifers were richer than arthropods in sediment samples, while the water samples were

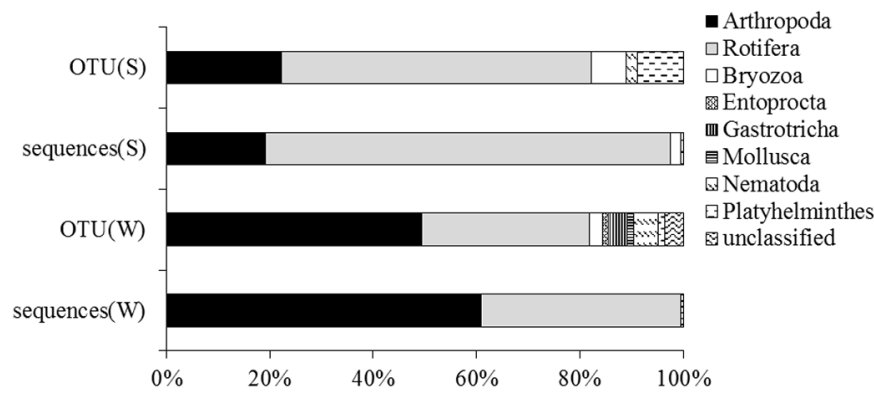

Fig. 3. Different taxonomic numbers from sequences and OTUs in the water and sediment samples (S: sediment; W: water).

the opposite. Species richness in the water samples was higher than that in the sediment samples $(p<0.01)$ (Tab. 2).

\subsection{Comparison of phyla levels}

In general, a similar trend of richness at different sites in Baiyangdian Lake showed that invertebrates in the waters were more abundant than their resting eggs in the sediments (Fig. 4a). The greatest difference in richness was at site B4. The richness of W5 was the highest, while S4 was the lowest. In all water samples, the most abundant phylum was Arthropoda, while in all sediment samples, the most was Rotifera (Fig. 4b). OTU richness of Arthropoda in every water sample was twice as high as that in the corresponding sediment sample, while OTU richness of rotifers in every sediment sample approached the richness in the corresponding water sample (Fig. 5).

\subsection{Comparison on genus levels}

The 23 genera appeared in common in all water and sediment samples and included Epiphanes, Keratella, Diaphanosoma, Conochilus, Brachionus, Pentatrocha, Ptygura, 
Sinocalanus, Filinia, Collotheca, Floscularia, and Neodiaptomus (Fig. 6). Epiphanes and Keratella were the most common genera in all water and sediment samples that showed relatively high abundance. Thermocyclops crassus and $K$. quadrata dominated the water samples, while $P$. gigantea and $B$. urceolar dominated the sediment samples.
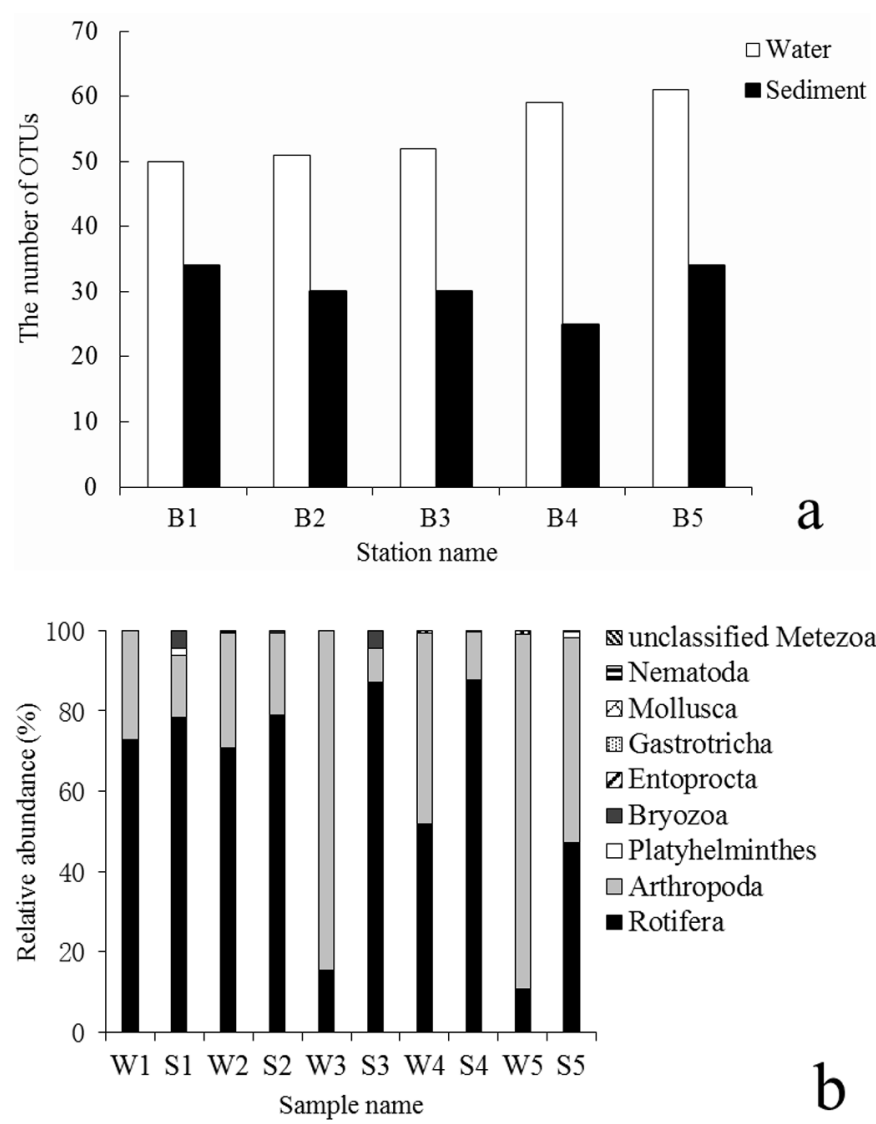

Fig. 4. The distribution of invertebrate phyla in water and sediment samples. (a) The OTU distribution of invertebrate phylum level; (b) Relative abundance of invertebrate phyla in the water and sediment samples. The abundance is presented in terms of percentage in total effective sequences in a sample.
The most abundant active invertebrate genus in the waters was Thermocyclops, and the next was Keratella. A total of 22 unique genera appeared in the water samples, including Thermocyclops, Mesocyclops, Eucyclops, Microcyclops, Lecane, and Pseudodiaptomus. In the sediments, the most abundant genus was Brachionus, and the next dominant genus was Pentatrocha. The total of 10 unique genera that appeared in the sediment samples included Lophopus, Phaenocora, Synchaeta, Gieysztoria, and Ilyocypris.

The hierarchical heatmap was based on the top 50 abundant invertebrates at the genus level, which were classified into two groups (Fig. 7). The closer the color is to red, the higher the relative abundance of the species in the sample. The first group was mainly the water samples, and the second group was sediment samples. The water samples at site B1 and B2 were clustered closely. The sediment samples at site B3 and B4 had similar species composition. The highly relative abundance of Keratella and Mesocylops in water samples were visualized and represented by warmer colors. Pesudodiaptomus and Microcyclops were rare in sediment samples as represented by blue blocks (Fig. 7). It reflected the species composition and abundance trend in keeping with the community barplot (Fig. 6).

\subsection{Venn diagram analysis of invertebrates}

Generally, 54 unique OTUs only appeared in the water samples, while 16 OTUs only appeared in the sediment samples, and 29 OTUs were both in the water and sediment samples (Fig. 8). There were 24 invertebrate species derived from the 29 common OTUs, including $K$. quadrata, $B$. urceolaris, C. campanulata, E. senta, F. longiseta, C. tenuilobata, Trichocerca elongate, and P. libera. Twentyone common invertebrate OTUs were in W5 and S5 samples, 40 unique OTUs in W5, 13 unique OTUs in S5 (Fig. 8). Site B5 had the largest number of common species both in the water and sediment.

\subsection{Diversity indexes of invertebrate assemblage}

The diversity index of Sob showed a relative similar trend with the OTU richness (Tab. 2). The number of invertebrate OTUs in all water samples was higher than that in all sediment samples $(p<0.01)$, while at site B3 and B5, Shannon-Wiener

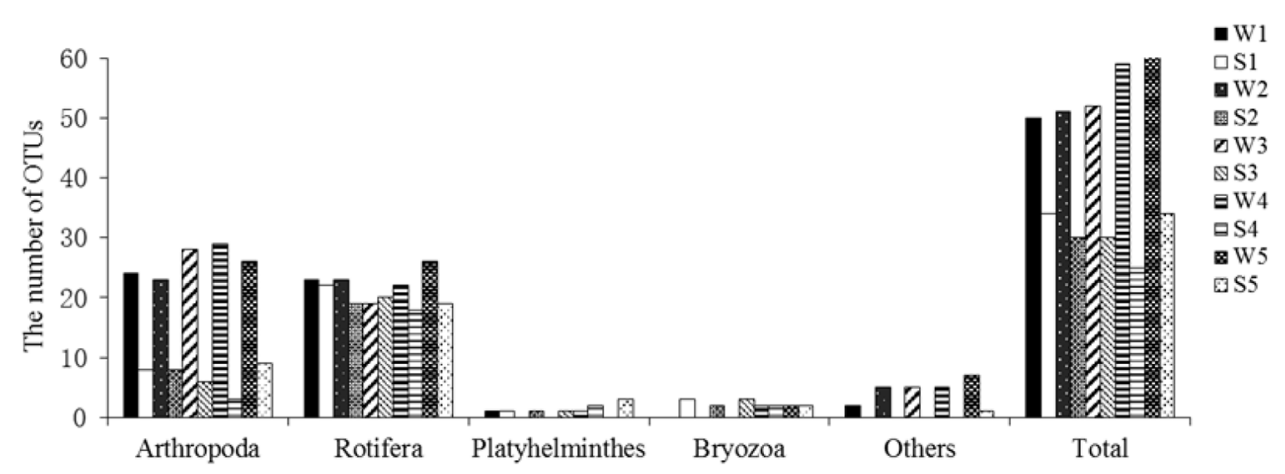

Fig. 5. The number of invertebrate OTUs on phylum level in different samples. (Others included: Entoprocta, Gastrotricha, Mollusca, Nematoda and unclassified Metazoa OTUs). 
index, Simpsoneven and Shannoneven indices of invertebrates in the water was lower than that in the sediment. The Simpson index of invertebrates in the water was higher than that in the sediment, due to the lower distribution uniformity of invertebrates in the sediment at the two sites as the Shannoneven index showed (Fig. 9). The diversity difference of invertebrates between the water and the sediment at B3 was the highest. Overall, the Shannon-Wiener index in the water (3.811) was higher than that in the sediment (2.927).

\subsection{Species difference analysis}

The Wilcoxon rank-sum test was used to analyze the significant difference of species between the water and sediment samples (Fig. 10a). The original hypothesis of this

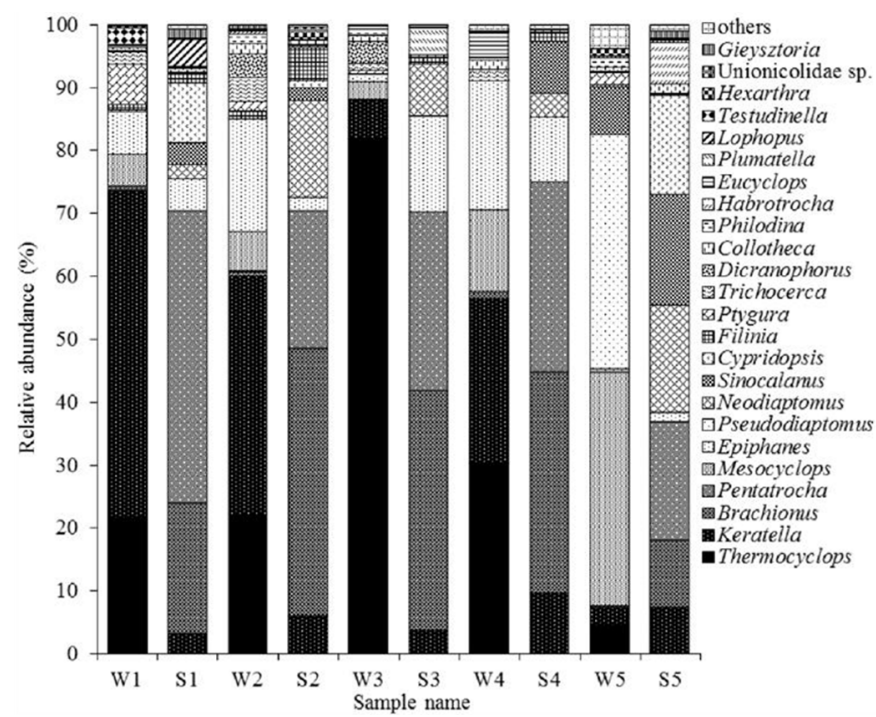

Fig. 6. Relative abundance of different genera in the water and sediment samples. The abundance is presented in terms of percentage in total effective sequences in a sample. analysis is no significant difference in the species distribution of independent samples between the two groups. So, the smaller the $p$ value is, the greater the difference between the

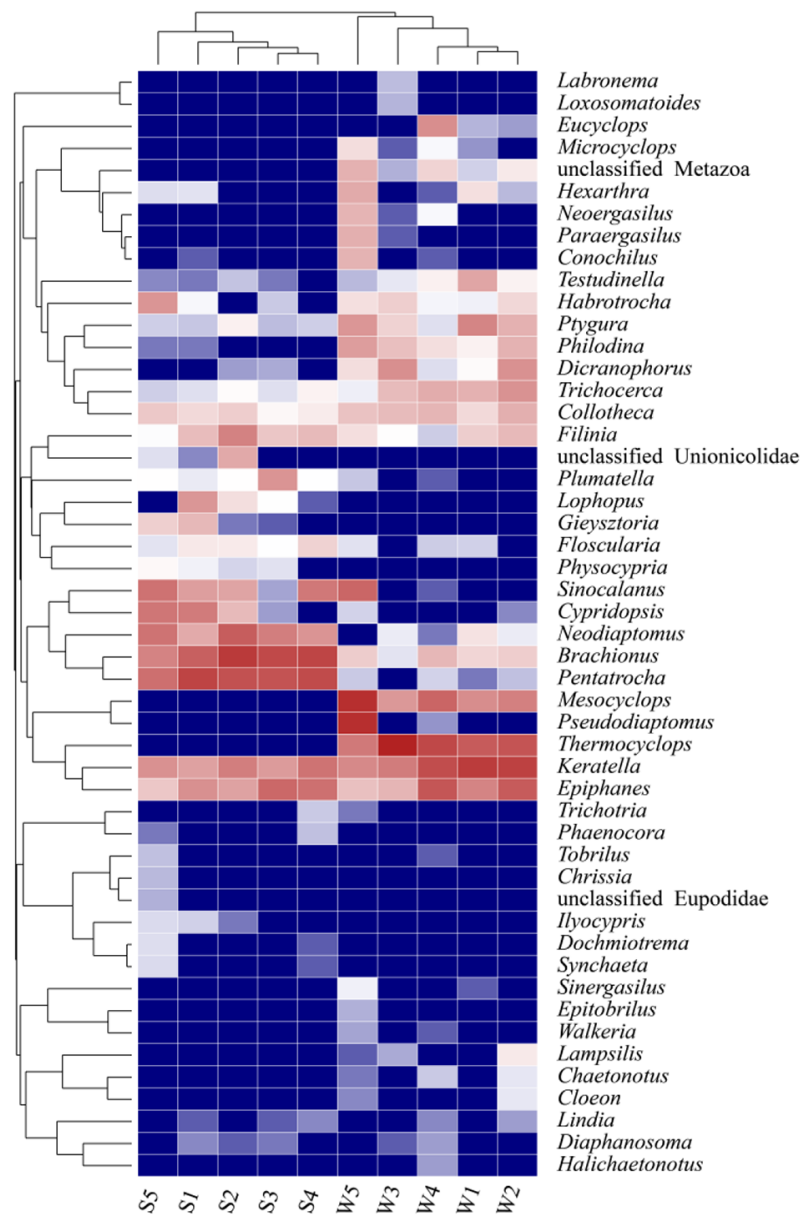

4.5
4.0
3.5
3.0
2.5
2.0
1.5
1.0
0.5
0.0
-0.5

Fig. 7. Heatmap analysis of invertebrate communities based on the Bray-Curtis of Illumina sequencing profiles. Relative abundance of different genera (top 50) in the water and sediment samples.

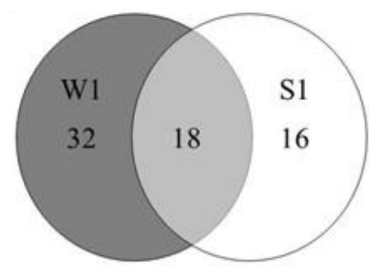

a

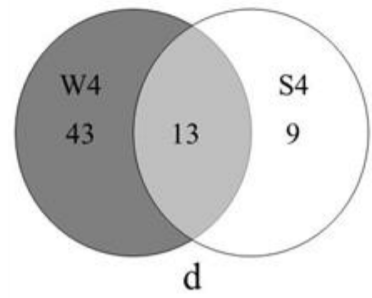

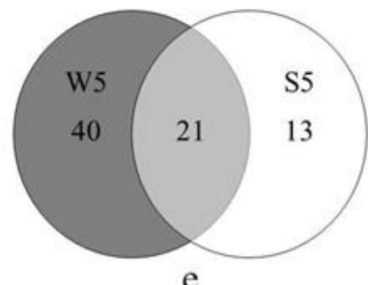

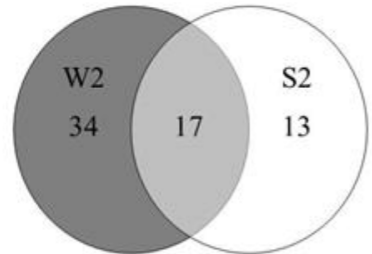

b

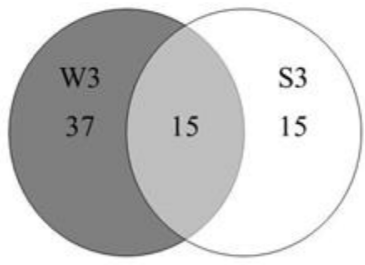

C

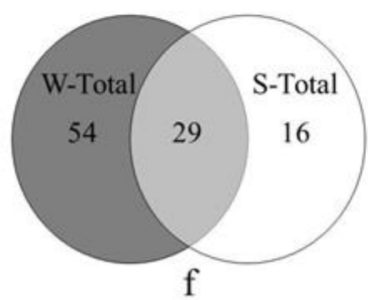

Fig. 8. Number of shared OTUs between water and sediment samples at five sites. (a) B1; (b) B2; (c) B3; (d) B4; (e) B5; (f) all samples. 

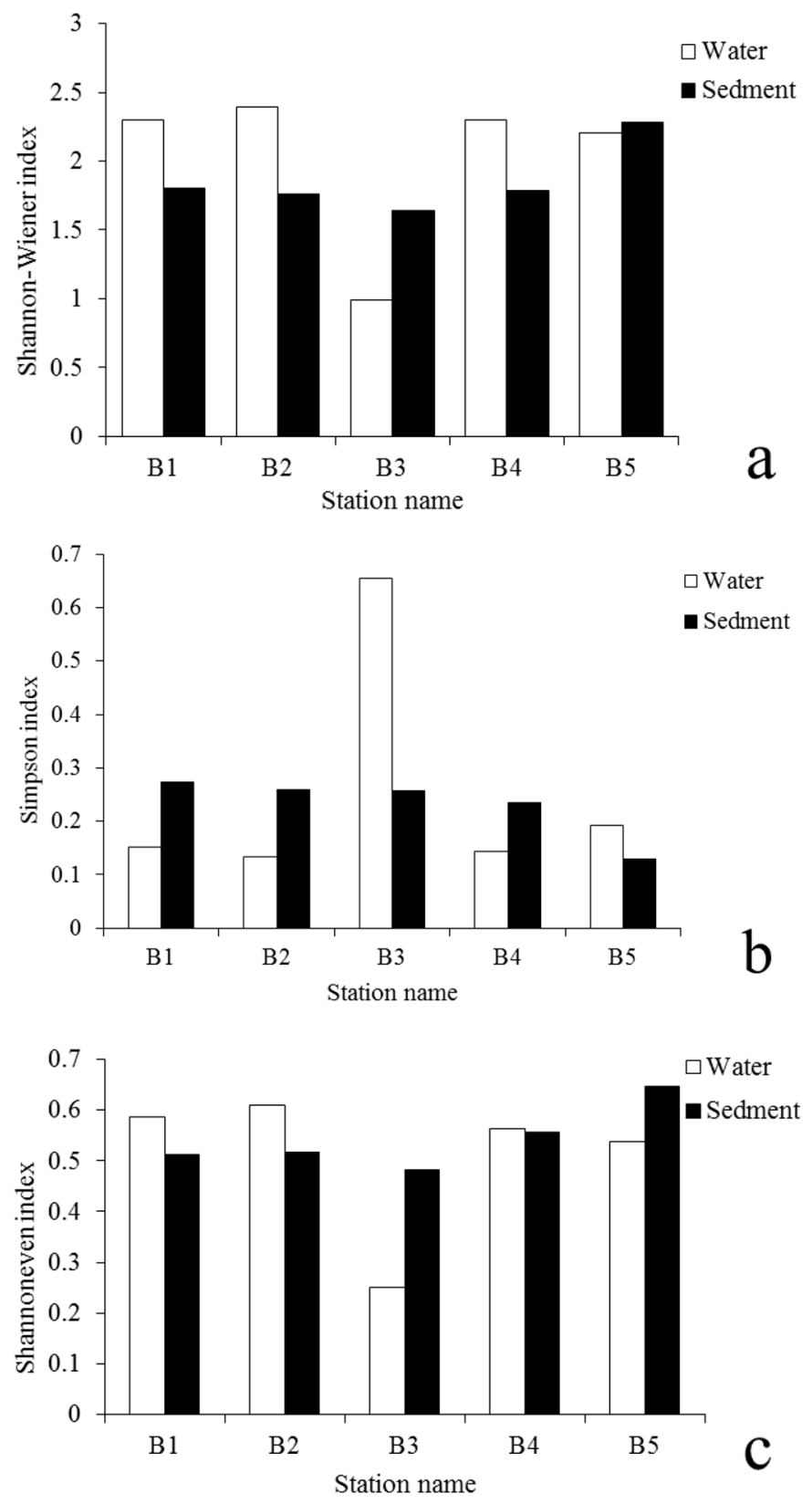

Fig. 9. The diversity indexes of invertebrates in the water and sediment samples. (a) Shannon-Wiener index; (b) Simpson index; (c) Shannon even index.

two groups of samples. Thermocyclops crassus and $K$. quadrata were the dominate species in the water samples, while $P$. gigantea and $B$. urceolar were the dominate species in the sediment. Thermocyclops crassus, M. dissimilis, $M$. pehpeiensis and $P$. inopinus were unique species in all water samples. To the contrary, there were a large number of $P$. gigantean and B. urceolaris found in the sediments, which were fewer in the water samples. Thermocyclops crassus, $M$. dissimilis and $M$. pehpeiensis were the most significantly different between the water and sediment samples. Epiphanes senta showed no significant difference.

The top 15 abundant species were all significantly different between water and sediment samples at B3 (Fig. 10b). Results from the Fisher's exact test to compare relative abundance difference and significance level of species were consistent with the diversity index. The most significant difference of the Simpson index between the water and sediment samples in all sites was at B3 (Fig. 9b).

\section{Discussion}

DNA metabarcoding provides an alternative method for rapidly identifying species and assessing biodiversity (ElíasGutiérrez et al., 2018; Bucklin et al., 2019; Carroll et al., 2019). Using 18S rRNA gene sequences, Sun et al. (2014) investigated the community dynamics of prokaryotic and eukaryotic microbes in an estuary reservoir. Djurhuus et al. (2018) found that the richness observed from the 18S rRNA gene data was higher than that obtained from traditional morphology and confirmed that DNA metabarcoding was an effective technique for future biodiversity assessments with the metabarcoding of the $18 \mathrm{~S}$ rRNA and cytochrome oxidase I genes. Also, Cheung et al. (2010) explored the composition and genetic diversity of picoeukaryotes in coastal waters of the subtropical western Pacific by the hypervariable V4 region of 18S rRNA gene. Copepod larvae are difficult to distinguish by microscopy. For example, the morphologically very similar M. dissimilis and M. pehpeiensis can be distinguished by HTS. The traditional method for identifying resting eggs is laboratory hatching by morphological identification (Ning and Nielsen, 2011). However, some resting eggs have longer hatching stages and lower hatching rates (Hairston and Kearns, 2002). HTS proved to be more accurate and more efficient for determining biodiversity in our research.

Zooplankton was the major component of aquatic invertebrates. The changes in the zooplankton population dynamics, community structure and function reflect water quality and its developmental trend (Lee et al., 2012; Yang et al., 2017; Berraho et al., 2019). Sibling species are universal, which increases the difficulty of identification (Grant et al., 2011). DNA metabarcoding reveals the true diversity of zooplankton assemblages (Lindeque et al., 2013). Universal primers and HTS provide an alternative for efficient biodiversity assessment because a trace of DNA in the sample can be detected (Leray and Knowlton, 2017). For example, in previous studies, 110 species of rotifers were recorded from Baiyangdian Lake (Gu, 1982; Liu et al., 2010; Zhang et al., 2016). In the present study, 13 newly recorded rotifers were identified including $P$. gigantean, $C$. campanulata, C. tenuilobata, F. armata, Habrotrocha bidens, Hexarthra intermedia, Lindia tecusa, L. torulosa, P. gigantea, Philodina megalotrocha, P. beauchampi, P. libera, P. longicornis and Testudinella clypeata. Features of these species (especially in the same genus) were difficult to identify by traditional microscopy, such as $P$. beauchampi and P. libera. Twentyseven copepod species were found in previous studies (Zhang et al., 2008; Yi et al., 2010), adding 9 new copepods by our study through HTS, including $M$. dissimilis, M. pehpeiensis, M. varicans, Pseudodiaptomus inopinus, T. crassus, Neoergasilus japonicus, Paraergasilus medius, Sinergasilus polycolpus and $S$. sinensis. Many copepod larvae could be accurately identified by HTS, but were difficult by morphology. Therefore, our study provides the basic data 

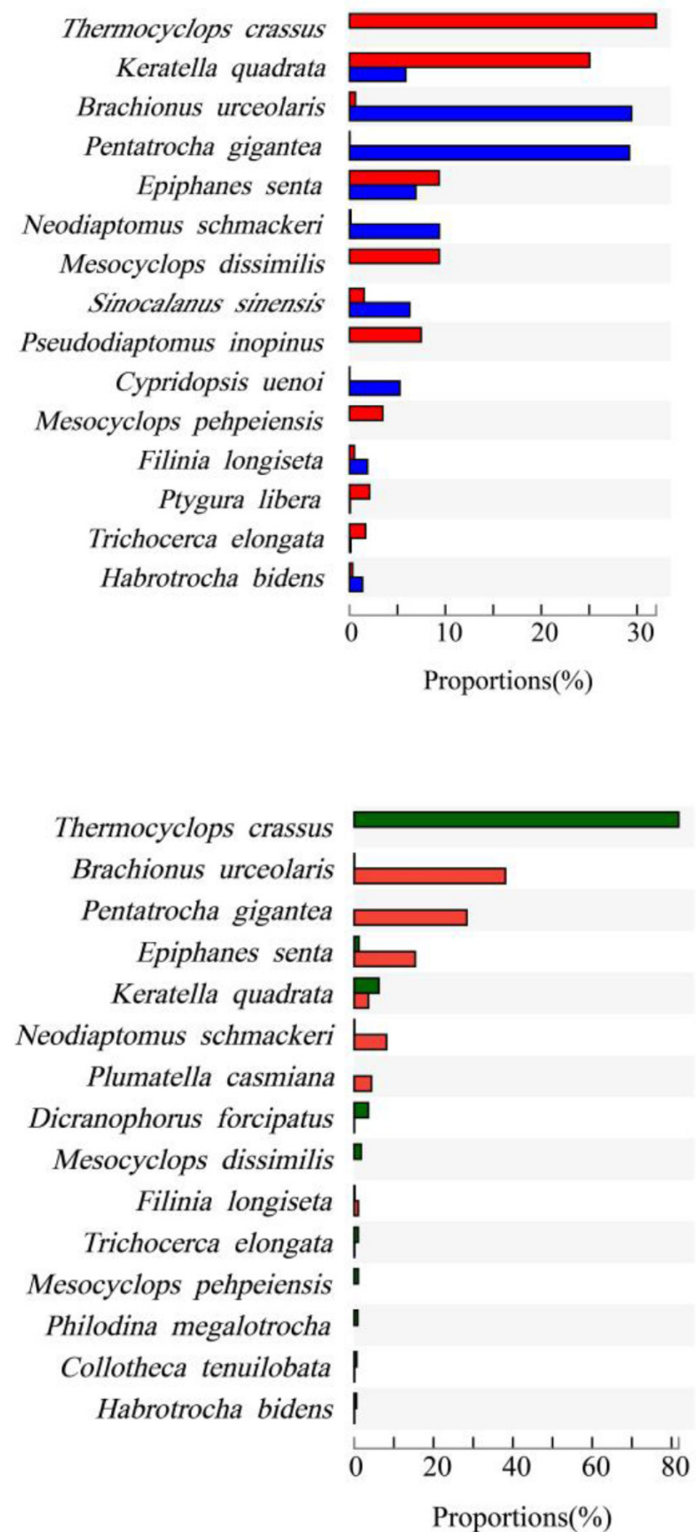
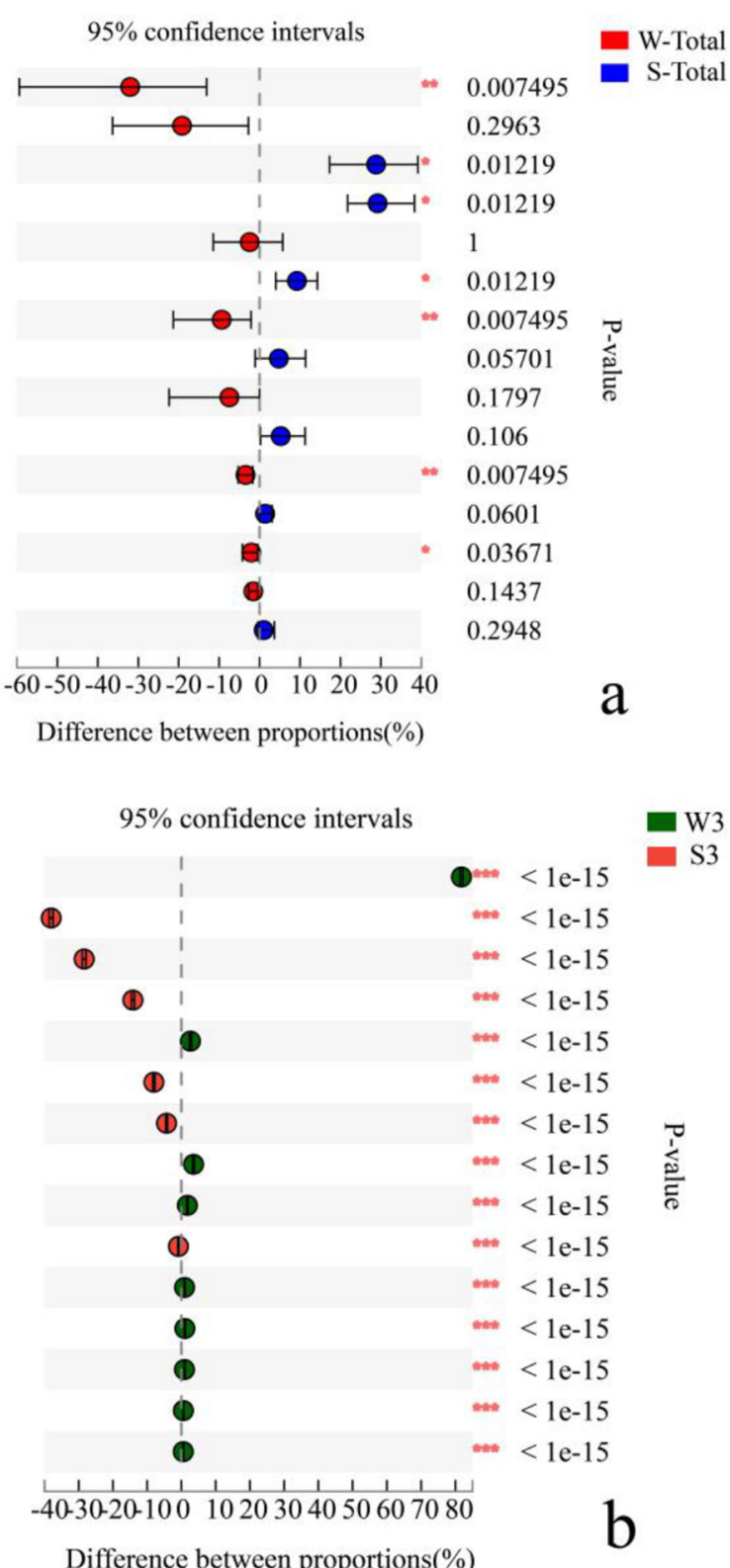

Fig. 10. Comparison of the differences in abundance of invertebrates at the species (top 15) level between water samples and corresponding sediment samples from the Baiyangdian lake. (*: $0.01<p<0.05, * *: 0.001<p \leq 0.01,{ }^{* * *}: p \leq 0.001$ ) (a) A comparison between communities using Wilcoxon rank-sum test; (B) A comparison among B3 communities using Chi-square test.

for rapid assessment of aquatic invertebrates in Baiyangdian Lake, an important habitat in north China.

The results were checked according to local reference literature to ensure that the recorded species were both local and credible. In previous studies, Thermocyclops was the dominant genus of copepods, and Brachionus was the dominant genus of rotifers (Wang et al., 2015), which was consistent with our study. Keratella, Brachionus and Mesocyclops were regarded as indicators of water pollution and eutrophication (Zhang et al., 2016). The water quality of Xili village (B1), Duan village (B2), Quantou town (B3), Wangjiazhai village (B4) and Lilang village (B5) are mainly polluted by local villages and towns. Poor water quality has resulted in a low biological richness of invertebrates, some of which disappeared because of the environmental changes.

Overall, the Shannon-Wiener diversity index in water was higher than in the sediment. The richness of invertebrate OTUs in all water samples were higher than that in all sediment samples $(p<0.01)$. Also, the higher diversity of aquatic invertebrates in water was observed in comparison with sediments. No significant difference in the Shannon-Wiener diversity index was shown at different sites due to the large difference of Shannoneven index. The low distribution uniformity in water at B3 showed low species diversity in water and balanced the overall difference. Invertebrate community structures were significantly different between 
water and sediment. Keratella quadrata and E. senta were the dominant species living in the water, so there were more corresponding resting eggs in the sediment (Fig. 10a). Thermocyclops crassus was the unique dominant species in water samples. Pentatrocha gigantean and B. urceolaris dominated in sediments as observed by the large number of resting eggs. The diversity of invertebrate resting eggs was lower in sediments due to lack of the resting egg stage of some invertebrates (Santangelo et al., 2015), or also that some invertebrate resting egg abundances were reduced by temperature-related seasonal succession (Zhang et al., 2018). A number of cyclopoid copepods enter diapause in one of the late copepodite stages without resting eggs (Frisch, 2002). For example, T. crassus enters diapause during winter as copepodite stages in sediments when water temperature is $<10^{\circ} \mathrm{C}$ (Kobari and Ban, 1998). Some copepod species are without diapause such as Eucyclops (Frisch, 2002). Resting eggs hatch quickly and re-enter the water when environmental conditions are suitable (Hairston and Kearns, 2002). Some resting eggs age gradually, die and decompose. Also, predation pressure reduces their densities (De Stasio, 1989), which display low abundances of resting eggs in the sediments and consequently only some invertebrate species are found in the water. Long-term observations of the invertebrate community are important in order to understand the changes in water quality (Ovaskainen et al., 2019).

Acknowledgements. This work was supported by Natural Science Foundation of China (41673080). We thank Yangguang $\mathrm{Gu}$ for help with generating sampling map. Our special thanks are given to Prof. Larry Liddle (Long Island University, USA) and Prof. Iain Suthers (The University of New South Wales, Australia) for their help to revise this manuscript.

\section{References}

Berraho A, Abdelouahab H, Baibai T, et al. 2019. Short-term variation of zooplankton community in Cintra Bay (Northwest Africa). Oceanologia 61: 368-383.

Bucklin A, Yeh HD, Questel JM, et al. 2019. Time-series metabarcoding analysis of zooplankton diversity of the NW Atlantic continental shelf. ICES J Mar Sci 76: 1162-1176.

Carroll EL, Gallego R, Sewell MA, et al. 2019. Multi-locus DNA metabarcoding of zooplankton communities and scat reveal trophic interactions of a generalist predator. Sci Rep 9: 281.

Chai ZY, He ZL, Deng YY, Yang YF, Tang YZ. 2018. Cultivation of seaweed Gracilaria lemaneiformis enhanced biodiversity in a eukaryotic plankton community as revealed via metagenomic analyses. Mol Ecol 27: 1081-1093.

Cheung MK, Au CH, Chu KH, Kwan HS, Wong CK. 2010. Composition and genetic diversity of picoeukaryotes in subtropical coastal waters as revealed by 454 pyrosequencing. ISME $J 4$ : 1053-1059.

Chust G, Vogt M, Benedetti F, et al. 2017. Mare Incognitum: A glimpse into future plankton diversity and ecology research. Front Mar Sci 4: 68.

De Stasio BT. 1989. The seed bank of a freshwater crustacean: copepodology for the plant ecologist. Ecology 70 : 1377-1389.
Djurhuus A, Pitz K, Sawaya NA, et al. 2018. Evaluation of marine zooplankton community structure through environmental DNA metabarcoding. Limnol Oceanogr: Methods 16: 209-221.

Egge ES, Johannessen TV, Andersen T, et al. 2015. Seasonal diversity and dynamics of haptophytes in the Skagerrak Norway explored by high-throughput sequencing. Mol Ecol 24: 3026-3042.

Elías-Gutiérrez M, Valdez-Moreno M, Topan J, Young MR, CohuoColli JA. 2018. Improved protocols to accelerate the assembly of DNA barcode reference libraries for freshwater zooplankton. Ecol Evol 8: 3002-3018.

Fontaneto D. 2019. Long-distance passive dispersal in microscopic aquatic animals. Mov Ecol 7: 10.

Frisch D. 2002. Dormancy, dispersal and the survival of cyclopoid copepods (Cyclopoida, Copepoda) in a lowland floodplain. Freshwater Biol 47: 1269-1281.

González CE, Escribano R, Bode A, Schneider W. 2018. Zooplankton taxonomic and trophic community structure across biogeochemical regions in the eastern South Pacific. Front Mar Sci 5: 498.

Grant RA, Griffiths HJ, Steinke D, Wadley V, Linse K. 2011. Antarctic DNA barcoding; a drop in the ocean? Polar Biol 34: 775-780.

Gu BY. 1982. Zooplankton in Baiyangdian Lake. Acta Agriculturae Boreali-Sinica 1: 90-98 (in Chinese with English abstract).

Hairston Jr NG, Kearns CM. 2002. Temporal dispersal: ecological and evolutionary aspects of zooplankton egg banks and the role of sediment mixing. Integr Comp Biol 42: 481-491.

Hajibabaei M, Shokralla S, Zhou X, Singer GA, Baird DJ. 2011. Environmental barcoding: a next-generation sequencing approach for biomonitoring applications using river benthos. PLoS one 6: e17497.

Hirai J, Kuriyama M, Ichikawa T, Hidaka K, Tsuda A. 2015. A metagenetic approach for revealing community structure of marine planktonic copepods. Mol Ecol Resour 15: 68-80.

Holm MW, Kiørboe T, Brun P, Licandro P, Almeda R, Hansen BW. 2018. Resting eggs in free living marine and estuarine copepods. $J$ Plankton Res 40: 2-15.

Kobari T, Ban S. 1998. Life cycles of two limnetic cyclopoid copepods, Cyclops vicinus and Thermocyclops crassus, in two different habitats. J Plankton Res 20: 1073-1086.

Lee SR, Oak JH, Chung IK, Lee JA. 2010. Effective molecular examination of eukaryotic plankton species diversity in environmental seawater using environmental PCR PCR-RFLP and sequencing. J Appl Phycol 22: 699-707.

Lee SR, Rho T, Oak JH, Lee JA, Lee T, Chung IK. 2012. Metagenomic examination of diversity within eukaryotic plankton from the Ulleung Basin in the East Sea of Korea. J Plant Biol 55: 310-315.

Leray M, Knowlton N. 2017. Random sampling causes the low reproducibility of rare eukaryotic OTUs in Illumina COI metabarcoding. PeerJ 5: e3006.

Lindeque PK, Parry HE, Harmer RA, Somerfield PJ, Atkinson A. 2013. Next generation sequencing reveals the hidden diversity of zooplankton assemblages. PloS one 8: e81327.

Liu C, Xing X, Wang J, Zhang Y. 2010. Characteristics of rotifera community structure in the Baiyangdian Lake. Acta Ecologica Sinica 30: 4948-4959 (in Chinese with English abstract).

MEE (The Ministry of Ecology and Environmental Protection of the People's Republic of China). 2002. Environmental Quality Standards for Surface Water (GB3838-2002), Beijing, China.

Mohrbeck I, Raupach MJ, Arbizu PM, Knebelsberger T, Laakmann S. 2015. High-throughput sequencing - the key to rapid biodiversity assessment of marine metazoa? PLoS One 10: e0140342. 
Ning NS, Nielsen DL. 2011. Community structure and composition of microfaunal egg bank assemblages in riverine and floodplain sediments. Hydrobiologia 661: 211-221.

Onbé T. 1978. Sugar flotation method for sorting the resting eggs of marine cladocerans and copepods from sea-bottom sediment. Bull Japan Soc Sci Fish 44: 1411.

Ovaskainen O, Weigel B, Potyutko O, Buyvolov Y. 2019. Long-term shifts in water quality show scale-dependent bioindicator responses across Russia-Insights from 40 year-long bioindicator monitoring program. Ecol Indic 98: 476-482.

Radzikowski J. 2013. Resistance of dormant stages of planktonic invertebrates to adverse environmental conditions. J Plankton Res 35: 707-723.

Santangelo JM, Lopes PM, Nascimento MO, et al. 2015. Community structure of resting egg banks and concordance patterns between dormant and active zooplankters in tropical lakes. Hydrobiologia 758: 183-195.

Savin MC, Martin JL, LeGresley M, Giewat M, Rooney-Varga J. 2004. Plankton diversity in the Bay of Fundy as measured by morphological and molecular methods. Microb Ecol 48: 51-65.

Sun Z, Li G, Wang C, et al. 2014. Community dynamics of prokaryotic and eukaryotic microbes in an estuary reservoir. $\mathrm{Sci}$ Rep 4: 6966.

Vandekerkhove J, Declerck S, Brendonck LUC, Conde-Porcuna JM, Jeppesen E, Meester LD. 2005a. Hatching of cladoceran resting eggs: temperature and photoperiod. Freshw Biol 50: 96-104.

Vandekerkhove J, Declerck S, Brendonck L, et al. 2005b. Uncovering hidden species: hatching diapausing eggs for the analysis of cladoceran species richness. Limnol Oceanogr: Methods 3: 399-407.
Wang YZ, Luo Y, Zhou XS, Zhang SL, Cui WY. 2015. Zooplankton biodiversity and water ecological evaluation in Baiyangdian Lake. $J$ Water Resour Water Eng 26: 94-100 (in Chinese with English abstract).

Yang J, Zhang X, Xie Y, et al. 2017. Zooplankton community profiling in a eutrophic freshwater ecosystem-lake tai basin by DNA metabarcoding. Sci Rep 7: 1773.

Yi L, Liu GQ, Xiang XG, Wang JX, Zhang YJ. 2010. The biodiversity of crustacean zooplankton in Lake Baiyangdian. J Hydroecol 3: 38-43 (in Chinese with English abstract).

Zadereev E, Lopatina TS, Oskina N. 2019. Dormancy in Aquatic Organisms. Theory, Human Use and Modeling. Switzerland: Springer $274 \mathrm{p}$.

Zhan A, Hulák M, Sylvester F, et al. 2013. High sensitivity of 454 pyrosequencing for detection of rare species in aquatic communities. Methods Ecol Evol 4: 558-565.

Zhang YW, Liu CQ, Xing XG, Wang JX, Zhang YJ. 2008. Cladocera and copepods in Baiyangdian Lake Hebei. Sichuan J Zool 27: 730-730 (in Chinese with English abstract).

Zhang TJ, Wang M, Peng YX, Liu LK, Liu JL. 2016. Survey of zooplankton community and evaluation of water quality in the upstream urban inland river of Baiyangdian Lake. Ecol Eng 34: $166-169$.

Zhang H, Urrutia-Cordero P, He L, et al. 2018. Life-history traits buffer against heat wave effects on predator-prey dynamics in zooplankton. Glob Chang Biol 24: 4747-4757.

Zhou Q, Lu N, Gu L, et al. 2020. Daphnia enhances relative reproductive allocation in response to toxic microcystis: Changes in the performance of parthenogenetic and sexual reproduction. Environ Pollut 259: 113890.

Cite this article as: Wang X, Wang Q, Yang Y, Yu W. 2020. Comparison of invertebrate diversity in lake waters and their resting eggs in sediments, as revealed by high-throughput sequencing (HTS). Knowl. Manag. Aquat. Ecosyst., 421, 19. 